\title{
REPRESENTAÇÕES DO COMER E ALIMENTAÇÃO EM RESTAURANTES DE COMIDA RÃPIDA NA CIDADE DE SÃO PAULLO: ALGUNS ASPECTOS SOBRE SAÚDE E OBESIDADE
}

\author{
Representations of food and eating in fast food restaurants in the city of São Paulo: some aspects on health and obesity \\ Janine Helfst Leicht Collaço' \\ 'Professora (Adjunta I) da Faculdade de Ciências Sociais da Universidade de Goiás (FCS/UFG), Membro do programa de Pós Graduação \\ em Antropologia da Social da mesma instituição. Coordenadora do grupo Consumo, Cultura e Alimentação (CNPq), pesquisadora do \\ Núcleo de Estudos de Antropologia, Patrimônio, Memória e Expressões Museais (NEAP/UFG).
}

\begin{abstract}
Resumo
O presente texto é derivado reflexões levantadas ao longo de várias pesquisas no sentido de compreender a relação entre comer fora, escolhas alimentares e vida urbana, retomando dados que não foram trabalhados anteriormente, em particular representações do comer em praças de alimentação e saúde. Sem esgotar o tema, discuto elementos recorrentes observados nos discurso dos interlocutores quando pensam a relação entre comer fora e saúde, tentando adequar estratégias para atender padrões e expectativas; expondo algumas questões que norteiam minhas atuais indagações em torno da relação entre corpo, alimento e saúde.

Palavras-chave: escolhas alimentares, consumo, obesidade, restaurantes de comida rápida.
\end{abstract}

\begin{abstract}
This text is derived from reflections raised over several researches in which undertook an effort to understand the relationship between eating out, food and urban life choices. In view of these previous results, I would like to explore data that were not worked and on that basis, I focused in representations of eating at food courts and health. Without exhausting the subject, I discuss some recurring elements observed in the speech of interlocutor's standards and expectations; exposing some questions that guide my current questions about body, food and health. Keywords: food choices, consumption, obesity, fast food restaurants
\end{abstract}




\section{INTRODUÇÃO}

Os dados aqui utilizados foram coletados em minha pesquisa de mestrado (COLLAÇO, $2003)^{1} \mathrm{em}$ praças de alimentação de shopping-centres, quando ficou claro a recorrente associação entre uma alimentação saudável e estados físicos entendidos como apropriados. O corpo físico dependia das escolhas que o corpo moral exercia, de modo a conquistar um reconhecimento que nem sempre estava ligado a um grupo, já que mostrar um corpo sadio e enxuto, além de ser público, é facilmente interpretado nos atuais códigos de beleza e juventude.

Desse modo, as escolhas alimentares entrelaçam ordens de vários níveis: material (aparência, preparo, qualidades nutricionais e químicas), simbólica (identidade, valores), incorporadas e absorvidas no corpo de maneira evidente: no gosto, nos estados corporais de curta e longa duração, na massa corporal - magro ou gordo, transformando o comer em um ato extremamente complexo. Assim, tentarei aqui um primeiro esboço de classificação para tentar entender alguns aspectos da materialidade corporal, pensando a relação entre o corpo físico e o moral; em seguida tratar as representações em torno do alimento e finalmente, como se entrelaçam as ideias e estratégias de consumo para consumidores de restaurantes de comida rápida, os fast-foods.

\section{O CORPO FÍSICO, O CORPO SOCIAL.}

Ao longo da mencionada pesquisa foi possível notar não só a recorrência com que o tema saúde e alimentação surgiam, mas a intensa ligação entre a interioridade de um "eu", manifestado pelos interlocutores como o responsável pelas suas escolhas e cuja inscrição corporal emerge no gosto, não extinguindo a relação interior/externo no momento em que o alimento era colocado na boca. Havia todo o processo pelo qual esse

\footnotetext{
${ }^{1}$ A decisão dos espaços a serem feitas entrevistas e observação participante foi pautada em três critérios: arranjos espaciais, orientação no eixo temporal e diversidade de frequentadores. Desse modo, tentei contemplar alguns padrões mais recorrentes de consumo alimentar, como o gênero, a idade e proveniência social, embora outros possam estar atuando, mas não incorporados neste momento. Foram selecionados três shoppings localizados na cidade de São Paulo: Morumbi foi elucidativo na forma pela qual se observam as dinâmicas espaciais no seu interior, orientadas pela divisão hierarquizada de suas áreas de alimentação. As variações no eixo temporal foram observadas nos três espaços, cada qual com sua especificidade. No Morumbi, os eixos trabalho/semana/formal/ "executivos" e lazer/ fim-de-semana/informal/
}

alimento iria passar, em uma evidente absorção de suas qualidades não só nutritivas, mas também simbólicas com efeitos físicos: sensações digestivas, eliminação do que não é aproveitado para fora do corpo e a influência na balança.

A adequação das escolhas internas e os resultados físicos alimentavam novamente esse "eu", de modo que sua subjetividade estava sempre em construção, em um diálogo entre o alimento, o corpo e as ideias que orientavam a prática, resultando na purificação ou mortificação da alma. A sensação de agir apropriadamente era evidenciada em muitas referências, "olha, hoje me sinto bem porque estou conseguindo fazer o regime direito, não é legal isso?" (Gisele) ${ }^{2}$, "eu tento comer devagar para não me entupir de comida e, fazendo isso, também não fico estressado" (Luís), mas quando ocorria um desvio de algo acreditado como certo, de uma norma, o sentimento que emergia era de uma falha, "Eu tenho muita dificuldade em me controlar quando estou nervosa, começo a comer, principalmente doces, e não paro. Depois parece que fico de ressaca, me sinto muito mal por fazer algo errado." (Ana).

Impor sanções ao corpo revelava um método educativo que visa dominar impulsos naturais e moldaria a alma. Duarte (2004) tratou desse assunto, embora em um contexto distinto, mas que pode ser útil para entender o corpo como convergência das "energias vitais" compreendidas como inatas do indivíduo e pertencentes à ordem da natureza. Ao serem passíveis de controle através da "moral" ou disposições similares, o "eu" estaria agindo na reiteração da ordem, uma vez que ao

\footnotetext{
2 "famílias" formaram um significativo contraste. O Pátio Higienópolis ressaltou a diversidade de uso em todos os horários, especialmente à tarde, quando as outras áreas de alimentação visitadas estavam quase totalmente vazias. Nesse momento o movimento é representado em sua maioria por pessoas mais velhas, vários estudantes que se dirigem à lanchonete McDonald's ou ao espaço onde estão instalados os jogos eletrônicos. Finalmente, no Metrô-Tatuapé registrei a presença de um público com perfil social distinto dos outros dois espaços selecionados, o que permitiu obter uma diferenciação na forma de uso da praça de alimentação ao longo do mês, com mudanças bruscas no movimento e aparentemente conectadas às remunerações mensais, uma vez que a população que costuma utilizá-lo lota o local durante o começo do mês, data que coincide com o recebimento de salários e escasseia à medida que se aproxima o pagamento.

As entrevistas foram realizadas entre maio de 2001 e junho de 2002 em praças de alimentação dos shoppings visitados. Embora alguns interlocutores tenham me permitido visitar suas casas ou trabalho, a grande maioria das informações foi obtida nos próprios espaços onde as pessoas estavam comendo, não sem algumas dificuldades ligadas a desculpas como 'estou com pressa', 'agora não posso', mas de maneira geral naquele momento houve boa receptividade. Vale ressaltar que nesse período ainda não era preciso submeter às pesquisas aos Comitês de Ética, prática hoje necessária.
} 
estabelecer limites para seus desejos primários no corpo, este em resposta, lhe daria mais subsídios para sua identidade.

Essa concepção, ainda sob a argumentação de Duarte (2004), toma o corpo como uma máquina que funciona a partir de informações dotadas pelos sentidos, sensações etc., adaptando-se a funções naturais, contudo com capacidade de pensar sobre si e criar ideias, de maneira que a "vontade" se mostra como forma de intervenção no mundo.

"O caráter crucial dessas disposições "morais" fez suscitar ao mesmo tempo, porém, uma ênfase peculiar na "interioridade" desse corpo, ambiguamente compreendida tanto como um plano de propriedades autônomas quanto como uma dimensão peculiar da fisicalidade fundamental de todas as coisas." (Op. Cit.: 42/43).

Dessa perspectiva, as sensações corporais ganham relevância e explicariam os impulsos vitais, fato que vem acompanhado de outro, a valorização do prazer e sua instituição ética. A ambivalência no ato de comer é assunto presente em autores como Fischler (1990) e Warde (1997), que se referiram à relação entre o que é certo comer, normalmente alimentos que os entrevistados dizem ser sem graça, como frutas, verduras, legumes, cereais, carne leve; ao contrário dos alimentos gostosos, mas que fazem mal.

A ambivalência, além do prazer e não prazer está também presente nos polos de doença e saúde; vida e morte; refletindo formas de tentar controlar através das escolhas individuais, a trajetória do corpo e sua saúde. Desse modo, se não é possível prever uma desordem, ao menos esse caráter errático pode ser diminuído frente à incorporação de controles no comer. Nesse sentido, dois pontos importantes no pensamento de Foucault convergem de algum modo para pensar sobre essa ambiguidade, ou seja, o que define os limites entre natureza e cultura, e qual é esse sujeito, já que para o autor ele não é mais do que um resultado do entrelaçamento de planos discursivos.

Assim, o autor amparado na produção de discursos do saber e do poder, elabora uma genealogia das transformações na forma de lidar com o corpo, apontando alguns elementos centrais para que se defina um novo tipo de poder, denominado de disciplinador, frente a outro chamado de soberano. Foucault (1991) ao entender o corpo como objeto de intervenção se interessa em seguir os passos que permitiram que esse poder disciplinador se instaurasse, de modo que realiza um amplo esforço no sentido de mapear a história e os seus pontos significativos para lidar com questões teóricas, construindo várias etapas nesse processo. Chamou a atenção para o vínculo entre o eixo espacial e temporal como fundamental para que se extraia do corpo o máximo de seu rendimento, pensando em especial na força de trabalho utilizada pelo modelo capitalista.

A importância passa, então, para o processo de corporificação. Interessa esmiuçar a relação entre instrumento e corpo, posturas, gestos, tempo gasto para um movimento. Não só é necessário estabelecer os passos dessas práticas, como é preciso vigiar a execução, a relação entre corpo e instrumentos e, a partir daí, gerar novos conhecimentos que serão utilizados para fortalecer a disciplina. Nessa reiteração através do saber, a disciplina é individualizante e o indivíduo torna-se alvo desse novo poder, cuja materialidade será inscrita corporalmente.

Nessa perspectiva, o corpo é uma máquina e que, portanto, precisa de combustível ${ }^{3}$.O que será colocado dentro da máquina precisa estar sancionado pelo saber científico, validando a importância de uma boa alimentação capaz de garantir o funcionamento adequado. Nesse caso, a desordem, do ponto de vista do comer, envolvendo a doença e a morte (já que o não prazer parece ser o preço a ser pago para ter uma boa saúde e um corpo funcionando adequadamente) pode ser evitada através de procedimentos que envolvem interferências que serão objetivadas no corpo: procedimentos de higiene adequada para com os alimentos, procedimentos de higiene para o consumo, formas de controlar o quê se come, como, quando, com quem, de modo a estabelecer práticas do comer certo, cujo efeito é visível no corpo.

No entanto, é preciso desmembrar esse saber, levando em conta que os corpos não se inserem em único conjunto, já que existem diferenças de classe social, gênero, idade. É dito o que deve ser feito, sabe-se o que é saudável, mas na prática essa orientação não é única a pautar as escolhas, embora crie disposições para se sentir mais ou menos orientado quanto ao que se deve comer e suas consequências. Aqui há uma questão que não contempla totalmente a teoria de Foucault (2005), pois uma vez que há um vigiar e um punir determinado na medida em que o conhecimento o ampara, revela-se certa agência ao sujeito, pois em

\footnotetext{
${ }^{3}$ Ver também Lupton (1996).
} 
alguma medida ele, ao fazer suas escolhas, permite abrir a brecha para uma dimensão mais dinâmica que escapa ao aniquilamento do sujeito sociológico, pois a reiteração jamais será igual, as condições vão se modificando e afetando a corporalidade. Por esse aspecto, é possível argumentar, então, que se a materialidade é de alguma maneira instável, pois depende de um ir e vir do externo ao interno, a punição deve emergir no corpo e, ao lidar com o comer, a marca do descontrole emerge na gordura. Esse estado anormal do corpo seria efeito da desordem, isto é, a falta de controle naquilo que está entrando no corpo e que a alma não está conseguindo frear, de modo que prevalecem os impulsos naturais no comando.

Nesse sentido, a educação ganha força e os mecanismos para perpetuar o fornecimento de corpos e, por isso a família e, sobretudo as crianças, desempenham papel importante na continuidade de fornecimento de corpos e interesse particular na educação dos filhos. Assim, o âmbito familiar é medicalizado e, por consequência, a alimentação. É preferencialmente nesse espaço onde devem ser introduzidos modelos educativos adequados, entre os quais uma boa alimentação e higiene considerada apropriada a fim de evitar contaminações ou outros riscos que coloquem em xeque a integridade física dos indivíduos. A preocupação com o descontrole da gordura e outras doenças que surgem pela falta de atenção ao que será colocado dentro do corpo adestra corpos desde cedo. O sujeito é reconstituído ao pacto social e as formas de punição criam os limites para a prática, de modo que se educa e transforma. Qualquer desvio dessa ordem é tomado como algo a ser transformado, sobretudo através do processo que exige disciplina e vigilância.

Sob outro prisma, Falk (1994) preocupado com a questão da constituição do sujeito e sua relação entre cultura e consumo, analisou a obra de Foucault que o orientou em algumas questões importantes na formulação de seus problemas. Conforme sua interpretação, o corpo surgiria na produção de Foucault como o objeto último de toda intervenção de fora envolvendo todas as práticas de poderes e saberes com o intuito de "discipliná-lo", exercendo certa regulamentação na subjetividade - aqui como estruturação psíquica - e considerando a alma como prisão do corpo e não o inverso. O corpo seria extensão da ordem, uma domesticação de um animal, em uma clara retomada das ideias de Nietzsche.

O problema levantado por Falk é que qualquer classificação do corpo humano seria decorrente de uma intervenção discursiva. Nesse sentido, Foucault embora tenha desenvolvido uma ferramenta de análise bastante elucidativa para compreender uma genealogia do sujeito moderno como um processo de objetivação, ou seja, como é produzido um objeto tanto de dominação como de conhecimento, permaneceu problemático o dualismo no qual o externo (cultura/sociedade) definiria lugar e condições para que se pressuponha esse tal sujeito em sua autoconstituição e em sua filosofia. Assim, se há um contínuo entre a estruturação da subjetividade e das estratégias intervencionistas (cujo alvo é o corpo), não haveria necessidade de definir um lugar para a constituição do sujeito. O sujeito seria um produto da própria indefinição do corpo, diante da ausência de estabelecer uma relação com o meio externo e com o próprio eu. Essa eliminação do lugar em Foucault, segundo Falk, deixaria escapar outras dimensões da produção de subjetividades, além de não perceber um espaço no qual há mais ou menos uma margem de manobra e algum grau de liberdade para o desenvolvimento desse sujeito. Falk lembrou, ainda, que Foucault parece ter notado essa questão e ter começado a trabalhá-la antes de poder finalizar suas reflexões, deixando seus pensamentos incompletos e retomados por outros autores.

Para Foucault, ainda, é clara a ideia de que não se pode estabelecer um controle sobre qualquer coisa, já que é preciso, inicialmente, classificar para poder organizar e, então, exercer a disciplina com o intuito de obter corpos dóceis e, com isso, retirar poder do indivíduo. É assim que Foucault busca na genealogia desse poder as formas de controle específicas que tomam o corpo como alvo de manipulação no plano físico para, através desse meio, domesticar o corpo incorpóreo, a alma. Abandona-se o suplício, o corpo espetáculo, despedaçado e submetido a castigos intensos e prolongados, para outros mecanismos de punição, do corpo esquadrinhado, do corpo que tem uma relação que busca eficácia através da previsibilidade proporcionada por tipologias. O castigo será através da disciplina corporal, uma vez que o corpo escapou ao seu padrão e nessa nova forma de controlar, vigora a produção de conhecimento organizado que pretende antecipar crises, aleatórias e inesperadas, portanto, desordens.

O conhecimento científico produzido sobre os efeitos da alimentação no corpo criou meios reguladores a fim de perpetuar a eficácia no fornecimento de corpos prontos para dar o máximo de si e, assim, se revela outro meio pelo qual o obeso 
é visto com desconfiança, já que seu corpo não atende as premissas estabelecidas. Nesse sentido, segundo Bordo (1993), o corpo da mulher se torna particularmente fácil de manipular, de modo que se implanta o terror à gordura.

Sob essa perspectiva, o excesso de massa corporal passa a ser um problema que deve ser solucionado através de rigorosos acompanhamentos, restringindo alimentos que contenham açúcar ou gorduras. Para quem deseja manter o peso, basta apenas evitar esses alimentos, embora fontes de prazer, não deveriam ser permitidas para quem precisa perder peso, pois supostamente já consumiram excessivamente esses alimentos que agora precisam ser eliminados de seu corpo. Acreditando nessa premissa, muitas pessoas preocupadas com sua imagem social não hesitam em submeter-se a esse tipo de restrição com um objetivo específico: restaurar o corpo e, também, a identidade.

É interessante notar também que o medo de adquirir um estado corporal desproporcional e ser estigmatizado não foi uma referência somente feminina, muitos homens apresentaram a mesma preocupação ${ }^{4}$. É quase sistemático em nossa sociedade criar constrangimentos de todo tipo aos obesos, além de ter implicações em suas trajetórias sociais. Comer e seus resultados no corpo físico delimitam características positivas do corpo moral: força de vontade, disciplina, disposição, interesse, busca por objetivos.

Ante o exposto, permanece a ideia de limites que o corpo possui e que nos dados coletados tende a ser marcada pela oposição dentro e fora, embora sejam construções flexíveis e arbitrárias, longe de se manterem estáveis, pois nem a própria oposição entre natureza e cultura são permanentes. O que está indo para "dentro" do corpo mostra que a subjetividade está em plena construção em um diálogo entre o plano material e o plano simbólicos separados apenas por uma boca, que por si já caracteriza o próprio caráter incompleto da materialização dos corpos pela ambiguidade que provoca.

\section{CALORIAS, GORDURA, ACCUCAR E SAL - O VAI E VEM DOS ALIMENTOS.}

Segundo Nestle (2002), a transformação do comer saiu de um paradigma do "coma mais" para o de "coma menos" ,especialmente no decorrer do

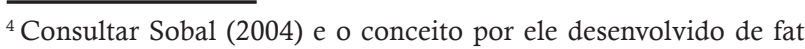
identity.

${ }^{5}$ Minha tradução: From "eat more" to "eat less".
}

século XX. Essa concepção encontra reforço nas políticas públicas adotadas pelos governos, preocupados com a crescente taxa de doenças crônicas que se dizem oriundas da má alimentação, ideia difundida e acentuada na imagem de uma epidemia de obesidade, isto é, um aumento de pessoas com peso acima do considerado normal por padrões normativos definidos por órgãos internacionais e adotados no Brasil.

Ao seguir a constituição histórica dessa alimentação saudável, resulta que não se pode dizer uma tendência unicamente contemporânea, pelo contrário, já que muitos modelos vieram e desapareceram ao longo da história. O que se convencionou, a partir de meados do século $\mathrm{XX}$, foi denominar uma dieta balanceada ou equilibrada segundo critérios estabelecidos por órgãos públicos europeus e norte-americanos a partir de estudos científicos, modelo também adotado no Brasil a partir dos anos 40. É segundo este modelo que se precisa equacionar o que se ingere e o que se gasta, privilegiando a presença de bons alimentos (frutas, verduras e cereais) em detrimento daqueles considerados maus (doces, gorduras, sal).

É curioso notar que calorias, vitaminas, colesterol, ômega 3, minerais etc., já estão incorporados ao discurso dos entrevistados, que atuam com estratégias diversas para tentar adequar seu gosto a um consumo alimentar que deve ser o certo, isto é, com frutas, verduras, legumes, cereais, pouca ingestão de carne e gorduras e, preferencialmente, nenhum açúcar.

De qualquer modo, certos alimentos saem e voltam à pauta, basta pensar em casos como o banimento do ovo e sua reconstituição à dieta recentemente; o próprio açúcar, de comida consumida por altas classes sociais, mais tarde alimento popular e hoje abominado; a questão da carne, que segundo a época é tida como nociva ao bom andamento do corpo ou como fonte de energia; o sal, de moeda para ingrediente indispensável na culinária ocidental e hoje culpado pelo aumento da hipertensão arterial. ${ }^{6}$ Tantas informações desencontradas que se cruzam originam uma cacofonia alimentar, como apontou Fischler (1990), embora

\footnotetext{
${ }^{6}$ Segundo Lenvenstein (2003) foi curioso notar que nos Estados Unidos essa alimentação balanceada estava assentada no consumo de carnes e derivados de leite, tentando impô-la aos imigrantes italianos, por exemplo, que se recusavam a consumir carne em demasia, especialmente quando tinham acabado de chegar aos Estados Unidos. Naquela época, sua alimentação era tida como pobre: verduras, vegetais, um pouco de queijo e muito azeite de oliva, para mais tarde, na década de 80, ser alçada a uma alimentação excelente em detrimento da anterior e pregada como aquela que traria maiores benefícios à saúde.
} 
comer certo nas entrevistas realizadas tenha ficado claramente ligado ao consumo de frutas, verduras, legumes, cereais e pouca carne e gorduras, além do tempo necessário para esse consumo como também o preparo adequado.

Calorias não eram nem ao menos conhecidas até $1896^{7}$, momento em que surge a primeira máquina capaz de medir o gasto calórico realizado pelo corpo humano e se dá inicio à carreira de nutricionistas, inicialmente gerada no interior dos cursos de economia doméstica. Estes, predominantemente compostos de mulheres recebiam orientações e informações sobre uma alimentação saudável, balanceada, equilibrada. Cozinhar deixava de ser um ato mecânico e passava também a ser uma façanha da química, abrindo o espaço doméstico para entrar em uma nova era, sobretudo capitaneada pela indústria.

O surgimento da nutrição e, por conseguinte, de uma parte da ciência dedicada aos valores nutricionais do alimento não foi um fenômeno repentino, contudo caminhou a passos largos a partir do século XX. Controlar o que é ingerido e sua ligação com estados corporais já estava nas recomendações de Hipócrates e no sistema humoral. Neste, para a aquisição e manutenção de uma saúde adequada era necessário equilibrar quatro elementos: calor, frio, o seco e o úmido em conjunto com quatro fluídos corporais: catarro (frio e úmido), sangue (quente e úmido), bile amarela (quente e seca) e bile negra (fria e seca). $\mathrm{O}$ balanceamento adequado desses elementos poderia ser interrompido por causas internas, assim como pelos hábitos do paciente ou por causas externas que poderiam ser derivadas de mudanças das estações do ano, o clima, o período do dia. Nesses casos, a dieta individual poderia redefinir o equilíbrio quando perdido, de maneira que essa relação entre as propriedades dos alimentos e seus efeitos já estava presente em torno das reflexões sobre a ingestão alimentar.

No século XVI essa alimentação foi redescoberta, o gosto e o sabor dos alimentos ficaram em segundo plano, prevalecendo uma preocupação em torno de necessidades fisiológicas e, portanto, em consumir alimentos apropriados. Um homem "civilizado" tomaria cuidado com sua alimentação, fenômeno que Mennell (1996) definiu como um "processo civilizador do apetite", sobretudo quando se passa de uma realidade na qual a fome era uma constante, para um período de fartura e abundância de alimentos, disponibilizados em escala muito maior, especialmente nos fins do século XVIII e

${ }^{7}$ Levenstein (Op. Cit). que se acentuou nos séculos seguintes, abrindo o acesso a ingredientes e produtos que raramente eram possíveis de adquirir, sobretudo entre as camadas menos favorecidas.

Emerge a classificação comer demais, possível graças à fartura de alimento disponibilizada a um número maior de pessoas. Gula, gulodice, o ser glutão são considerados hábitos de pessoas pouco educadas. ${ }^{8} \mathrm{O}$ conceito de dietas e regimes, embora possível de ser traçado desde um longo período, só recebeu uma atenção maior por volta do século XVIII, sob dois aspectos distintos: na França se desencadearia um movimento que valorizaria o refinamento do gosto, criando posteriormente a noção de uma cozinha diferenciada e requintada (haute cuisine). Na Inglaterra e nos Estados Unidos o desenrolar dos acontecimentos ocorre sob outro prisma, focalizando no interesse dos elementos nutricionais do alimento e as restrições na alimentação para obter uma boa saúde e surgem, assim, as classificações dos alimentos a partir de suas características elementares e não pelos seus valores distintivos. Em ambos os casos, contudo, verifica-se o controle da ingestão de alimentos organizados por diferentes tipos de conhecimento: um baseado na distinção, na etiqueta e boas maneiras; e outro apoiado no aprofundamento do conhecimento científico das qualidades dos alimentos.

Embora esses dois polos se desenvolvam de maneiras específicas, o que se nota hoje é uma convergência entre distinção e um comer saudável, já que o conhecimento da forma pela qual o corpo funciona e o que lhe faz bem se unem à noção de distinção, especialmente no fato de que é preciso se manter esbelto e cria em torno das pessoas com maior peso corporal condições para estigmatizá-las. Comer demais passa a ser associado às classes menos favorecidas, processo iniciado em países que presenciaram a Revolução Industrial e que permitiu ampliar a circulação de mercadorias antes restritas às classes sociais elevadas, como a farinha de trigo e o açúcar. ${ }^{9}$ Comer frutas e verduras frescas restringiu-se àqueles que possuíam tempo e disponibilidade de recursos para adquirir. Alia-se a essa situação, ainda, o desenvolvimento de uma indústria de transformação na área alimentícia que para poder garantir a provisão dos alimentos, recorre a técnicas de conservação e preservação que manipulam qualidades originais dos alimentos.

\footnotetext{
${ }^{8}$ Consultar também Brillat-Savarin (1995) que escreveu nos fins do século XVIII e traz definições do que na época era tido como glutão guloso e um gourmet.

${ }^{9} \mathrm{O}$ açúcar também encontrou maior apelo graças à combinação com outros produtos que passaram a circular com maior intensidade nesse período, como o café, o chocolate e o chá. Ver Mintz (1985).
} 
Durante esse período são feitas pesquisas sobre as qualidades dos alimentos, mas por volta de 1900 é que toma maior impulso e se estabelece nos Estados Unidos o que se definiu como "New Nutrition", segundo Levenstein (2003). Dieta praticada principalmente entre membros de uma classe média inspirados em um conjunto de ideias que atribui valor moral aos alimentos, reforçando a importância de muitos serem comidos crus ${ }^{10}$ para garantir ao máximo suas qualidades e o mínimo de intervenção da mão humana, é alçada sua importância quando se descobrem as vitaminas e sais minerais, entre 1911 e 1930. É também, por volta dessa época, que surge no Brasil, uma forma mais sistematizada de um conhecimento da alimentação da população brasileira em alguns trabalhos que tentavam descrever hábitos alimentares, segundo observou Vasconcelos (2002).

Surge no ano de 1918, a noção de "alimentos protetores", cuja capacidade era de evitar problemas por ausência desses nutrientes. A tendência de valorizar a comida no seu estado natural permanece em detrimento dos alimentos industrializados. Frutas e verduras que eram considerados alimentos raros e caros, transformam-se em alimentos "remédios"11 e passaram a ser recomendados diariamente, ao contrário do que era a orientação predominante no começo do século XX. Essa dieta era pensada como adequada aos trabalhadores braçais, uma vez que estes necessitariam de maior quantidade de energia proveniente de sua alimentação, ao contrário de trabalhadores sedentários, ou seja, uma relação inversa entre quantidade de calorias e prazer gastronômico, acentuada pela diferença de rendimentos.

Prevalecem nesse período preocupações em torno do desperdício, proliferando metáforas econômicas: o alimento é energia, é quantificado, medido, controlado com precisão, é submetido a procedimentos técnicos que possam garantir a higiene, evidenciando um processo que tenta racionalizar o comer. Assim, se a alimentação era uma questão humoral, isto é, de adequação entre o indivíduo e o meio, no século XIX torna-se um problema, já que é preciso doutrinar o indivíduo ao que se considera apropriado, uma vez que os corpos se transformam em máquinas produtivas.

No mundo contemporâneo todos esses elementos se aliam às mudanças introduzidas pelas repetidas inovações da indústria. Por exemplo, o

\footnotetext{
${ }^{10}$ Atualmente há uma retomada dessa ideia no movimento chamado crudivorismo, que prega o consumo de alimentos praticamente crus, brotos e sucos.

${ }^{11}$ Chen (2009) traçou as diferentes representações do alimento como remédio
}

medo do colesterol se intensifica a partir da década de 80, sobretudo nos Estados Unidos e se alastra rapidamente, assim como as restrições necessárias de serem adotadas nos hábitos alimentares para combatê-lo.

Com um leque bastante diversificado de opções alimentares, nem todas são consideradas apropriadas para a saúde e para a imagem corporal, emergindo os alimentos que, segundo Fischler (1990), são abominados: gordura, açúcar e sal. Por outro lado, oferecer uma massa corporal avantajada torna-se um suplício que, recentemente, passou à categoria de doença e, portanto, combatida, controlada, monitorada. A obesidade é tida como derivada dos maus hábitos alimentares e traz consequências: o surgimento de doenças crônicas como diabetes, problemas de circulação, digestivos, de coração, o próprio câncer além do comprometimento da imagem corporal e social da pessoa.

No Brasil, o impulso da nutrição foi visível a partir da década de 30, uma corrente que considerou duas vertentes: uma preocupada com o aspecto individual e outra mais ampla, tentando lançar luz aos hábitos alimentares sob uma perspectiva coletiva, segundo observou Vasconcelos (2002), embora tenham convergido para consolidar um campo específico para a nutrição no país e amparados por práticas implantadas no governo populista. Alguns cursos de Nutrição surgem em 1940, mas sem status de curso universitário. Posteriormente, emerge a profissão de nutricionista como curso universitário, pois até então a formação era prática, ora na área de dietética, ora na área de alimentação coletiva.

Preocupar-se com hábitos alimentares estava na agenda desse novo campo científico que emergia. Contudo, apesar de orientar populações menos favorecidas no consumo de dietas saudáveis, todos os programas lançados pelos governos, tanto nos Estados Unidos como no Brasil, obtiveram resultados pífios. Comer implica uma relação estreita entre o que está fora de nosso corpo e aquilo que, ao passar pela boca, será incorporado. O corpo físico abre-se ao mundo externo e deixa que nosso espaço sensível receba o externo. Nesse sentido, o gosto como inscrição no corpo, delimita pontos de proximidade e distância em relação ao Outro e não levar em conta essas diferenças, baseando unicamente no critério científico, mostrou a dificuldade que é lidar com essa questão.

É importante notar que a análise de Foucault foi e é importante para fornecer elementos que conduzem a ação dos discursos sobre a regu- 
lamentação corporal, contudo ao pensar a alimentação, nota-se que o entrelaçamento de camadas nas escolhas é inscrito no corpo, de maneira a objetivar diferenças e hierarquias, quer seja no gosto, em sensações corporais, na incorporação simbólica de qualidades ou na imagem estética. $\mathrm{O}$ conhecimento científico tem seu impacto, porém diluído nas práticas do dia a dia, sem dúvida organizando ideias, criando disciplinas e controles que também não se limitam a um único espaço normativo do corpo humano.

Esse controle, como ficou explícito nas praças de alimentação, também ocorre de maneira velada, mesmo entre mundos sociais distantes que, em alguma medida, reconhecem códigos. $\mathrm{O}$ discernimento dos interlocutores ao referir-se às pessoas com excesso de massa corporal de que possuem algum distúrbio e precisam ser tratadas, além do medo de vir a tornar-se parte desse grupo, foi evidente. Essa preocupação orienta algumas escolhas, mas evidentemente que algumas escapam ao esquema, sendo o ponto fecundo o fato de que quase todos os entrevistados criavam mecanismos de controle internos que dialogavam entre o deixar-se levar pelos seus desejos, de modo que emerge um "eu" enfraquecido, ou manter a rigidez da dieta imposta pelo próprio "eu" que se mostra fortalecido pela observação do comer certo.

\section{COMER EM PRAÇAS DE ALIMENTAÇÃO EM FAST-FOODS: ALGUMAS RELAÇÕES ENTRE ALIMENTO E SAÚDE}

A obesidade, no mundo contemporâneo, é tida como um desvio da normalidade, ser magro parece, para alguns, a busca do Santo Graal. De algumas décadas para cá, a partir dos discursos acadêmicos produzidos no meio médico, a obesidade passou a ser medicalizada, como já apontado por Poulain (2002) e, como doença, demanda intervenções terapêuticas capazes de devolver ao corpo sua normalidade. Desse modo, multiplicam-se os exames clínicos que identificam anomalias relacionadas às doenças decorrentes da má alimentação e que são efetuados a título de prevenção. Quando já se está em uma faixa considerada de pessoa obesa, além dos exames para controlar taxas de açúcar e gorduras no sangue, outros tratamentos terapêuticos são recomendados, alguns bastante drásticos como as cirurgias que reduzem o tamanho do estômago, remédios que regulam o apetite, espaços dedicados aos tratamentos terapêuticos como spas, consultórios de psicólogos e psiquiatras dedicados às desordens alimentares.

Aceitação social é um fato difícil para pessoas acima do peso, consideradas espécies de abjeções, especialmente para as mulheres, normalmente as primeiras a apresentarem problemas com a alimentação, como anorexia e bulimia. ${ }^{12}$ A gordura medicalizada produz suas patologias e é comum sua associação a problemas de ordem psicológica como a depressão e a ansiedade, pilares de um conjunto de imagens em torno do problema de ser gordo, uma vez que essa situação não depende só da vontade de melhorar, pois outros aspectos se reúnem para contribuir no fracasso de dietas, regimes e tratamentos para perder peso.

Muitos entrevistados com dificuldades em manter o peso considerado normal afirmaram que a raiz do problema é outra, chamando a atenção uma entrevistada, que definiu seu problema como síndrome de compulsão:

"(...) sabe? Eu não posso começar a comer chocolate ou doce, se começo não paro mais, como uma torta inteira, um pote de sorvete, um saco de biscoitos (...,), por isso tomo antidepressivos... para não fazer essas coisas, ainda bem que tem jeito, não é?(...) Daí o médico falou, a comida pra mim é vício e, por isso, sou que nem alcoólatra, não posso dar a primeira mordida, se não já viu, né?" (Ieda)

Nesse sentido, a produção de um saber científico que transborda os limites dos consultórios médicos e invade a televisão, a mídia, as conversas do cotidiano, criam raízes que se colam às ideias sobre o quê comer. É preciso, rezam entendidos, livros, revistas, programas de televisão etc., ter uma alimentação adequada como primeiro passo para manter a saúde. Esse conhecimento se revela entre os interlocutores na adoção de hábitos saudáveis, cujos benefícios seriam não só de evitar a doença, como atingir equilíbrio ao não sobrecarregar o organismo com lixo, e desse modo, evitar a aquisição de peso, assim como manter sempre a juventude. Raramente ou nunca se comentava sobre o desenvolvimento de doenças como câncer, ao que parece um tema abordado com dificuldade.

Ser gordo ou falar sobre gorduras sempre trazia à tona sentimentos negativos, além de ser um problema, era considerado um defeito cuja

\footnotetext{
${ }^{12}$ Ver Bordo (1993) para um aprofundamento do assunto, assim como Counihan (1997), Gonçalves (2004) também oferece resultados de sua pesquisa com pacientes que fizeram ou estavam sendo preparados para a cirurgia de redução estomacal.
} 
culpa, muitas vezes, não dependia da vontade da pessoa, já que todos mencionavam casos de pessoas malsucedidas com programas de emagrecimento que provavelmente teriam disfunções genéticas ou hormonais. Tentativas frustradas de perda peso eram descritas como luta para eliminar os quilos indesejados, mas inevitavelmente quando o fracasso era evidente, a justificativa imediata era de "sou gordinha (o), mas saudável", um modo de contornar o fato de que gordura é doença, sugerindo uma questão interessante que manifesta a forma pela qual a pessoa se refere ao seu estado físico: estar gordo sugere que se está sob um período transitório e ser gordo já define uma identidade social, a partir do estado corporal que não mudará, em geral, referência entre pessoas que já tentaram vários métodos de emagrecimento sem resultados promissores. Estes últimos emendavam comentários sobre índices obtidos em exames de colesterol, glicemia e outros, melhores do que de muitos magros por aí e reforçando de que essa relação entre excesso de massa corporal e estado de saúde não necessariamente é negativa.

Outro aspecto é a percepção do processo digestivo para definir se houve uma ultrapassagem dos limites na hora da refeição. Sentir peso ou dizer que está estufado, comer além da conta seriam indicativos de que houve um consumo exagerado de alimentos e, consequentemente uma ingestão excessiva de calorias. Ao contrário, leveza, digestão fácil, daqui a pouco estou com fome seriam indicativos de que se está seguindo a disciplina, observando corretamente o comer equilibrado. Comer exageradamente, consumir alimentos pesados ou porcarias forneceria calorias a mais daquelas necessárias e ao não serem utilizadas, o resultado são quilos a mais, já que elas iriam para uma espécie de estoque nas células gordurosas que "estão sempre esperando de boquinha aberta mais gordura". (Ediris)

$\mathrm{O}$ excesso de calorias, o pouco movimento físico, a ideia de que tudo que é gostoso acaba engordando mostram uma associação entre as qualidades do alimento, como também com a quantificação do que é ingerido. O controle se mostra na restrição dos impulsos de comer exageradamente, um aspecto que sempre vinha seguido dos truques para eliminar quando o desastre acontecia: pular uma refeição, jejuar durante um dia todo, tomar somente líquidos durante 2 ou 3 dias, exagerar nos exercícios físicos. $\mathrm{Na}$ época, um meio mais drástico de expurgar a gordura do corpo era tomar um remédio conhecido como Xenical, que atua na absorção de gorduras no intestino, após um. "daqueles almoços, sabe? Comendo de tudo, é... picanha, linguiça, feijoada, farofa, sabe ninguém é de ferro, mas também não quero engordar, daí quando como além da conta, carne, feijoada, que tem gordura né? Porque eu não ligo pra doce, eu mando um Xenical, mas tem que ficar esperto, porque quando você menos espera pode sair por baixo e daí é a maior vergonha (...)" (Herbert).

Segundo Boltanski (1989), a percepção do que se come e do que se elimina já está incorporada ao senso comum e poderia estar relacionada a um deslocamento de categorias médicas em desuso, como as definidas por Hipócrates, para o conhecimento popular, que delas se apropria para classificar e organizar grupos de alimentos. Por esse ângulo, a gordura seria quente e úmida; o açúcar, quente e seco, mas o importante seriam as propriedades que esses alimentos podem transmitir ao corpo através de sua ingestão. Por outro lado, essas categorias também convivem com aquelas colocadas pelos médicos, mas que são coladas a um conhecimento já difundido, espécie de processo no qual há uma diluição da categoria para algo mais próximo de modo a servir como referência cotidiana.

Desenha-se um quadro no qual a boa alimentação depende da seleção individual, contudo essa relação pode variar de importância segundo a classe social, o gênero e a idade do interlocutor: pessoas jovens e com posição social mais favorecida, sobretudo mulheres, se preocupavam muito com a aparência em primeiro lugar; jovens de classes populares gostariam de ter uma alimentação saudável, mas muitas vezes são impedidos por circunstâncias diversas: de ordem econômica, de tempo, de acesso a informações e produtos frescos etc.; pessoas mais velhas, independentemente da classe social, procuravam alimentar-se de modo adequado, embora os produtos consumidos tivessem bastante variação. Neste grupo, alguns controlavam a alimentação pelo peso dos alimentos, como $250 \mathrm{~g}$ no almoço e só, outros consumiam grandes quantidades de folhas verdes antes de servir-se dos pratos quentes, um modo de encher a barriga com coisas saudáveis e não comer bobagens. Assim, evitar óleos, frituras, porcarias, tranqueiras e guloseimas seria uma atitude coerente na tentativa de gerar um futuro melhor, repleto de qualidade de vida, com energia e vitalidade, livre de doenças e contratempos gerados pela má alimentação.

Verificou-se que comer certo tinha um 
caráter de conhecimento adquirido, sobretudo, de fontes médicas e científicas, embora diluído na orientação das práticas do cotidiano, já que nem tudo que se supõe certo, estava ao alcance das pessoas: algumas porque comiam fora de casa, outras porque não tinham refeições organizadas, outros com limitações econômicas. Mas, o discurso do que era comer certo, frutas, verduras, legumes, cereais integrais, pouco sal, pouca gordura e pouco doce, se fazia sentir de modo amplo. Além dessas recomendações, muitos interlocutores comentavam como contornar os efeitos causados por hábitos que levariam à aquisição de peso: "não como carboidratos à noite, pois quando se dorme não se gastam calorias, daí vira um estoque de gordura" (Vivi), "não misture carboidratos e proteínas porque engorda, coma só macarrão ou só carne que pode ser acompanhada de salada, mas só" (Marcelo), "evite jantar, de noite você não gasta aquilo que comeu à noite" (Vera), práticas que qualquer pessoa saudável deveria adotar, sempre levando em conta o gasto energético, já que comer certo era um jogo de soma zero para não engordar.

Selecionar o que comer e como comer passou a ser uma responsabilidade do indivíduo, o fato de não ter capacidade para elaborar seu cardápio ou não mostrar que consegue resistir aos maus alimentos, definiria a falta de força de vontade e a ideia de fracasso, imagens que normalmente apareciam associadas às pessoas acima do peso. É interessante notar que, independente da faixa social, gênero e idade havia sempre algum tipo de comentário em relação ao peso, à imagem corporal, ao tipo de alimentação que proporciona bem-estar, equilíbrio, no sentido de um grande poder civilizador, como trabalhado em Elias $(1993,1994)$, já que a alimentação se torna eminentemente um ato individual, mas condicionada a uma série de regras, não só de como comer, mas o quê comer, quando, com quem. Comer certo se impõe em diferentes níveis, entranhando uma forma de controle que age sobre o indivíduo e vai além de um grupo ou comunidade. ${ }^{13}$

Porém, se a escolha é mantida no plano individual e de algum modo se exerce certo controle sobre o consumo, o estigma da obesidade é social e carrega consigo a falta de controle que é necessária para estar bem em seu corpo. Desse modo, se a pessoa é magra demonstra sua afinidade com a cultura, afinal consegue manter sua disciplina e seu corpo o resultado de seu esforço, ao contrário do obeso que marca em seu corpo

\footnotetext{
${ }^{13}$ A esse respeito, consultar também o trabalho de Warde (1997) sobre gosto e consumo.
}

o excesso, o descontrole, a desordem e a marginalidade de sua boca, já que esta não consegue ser controlada pelo "eu" interior, ávido por tudo aquilo que é sabido não ser bom.

Obviamente, que esse poder disciplinador é ambíguo quando se observa o que a pessoa disse e o que ela de fato faz, mas não deixa de revelar todo um conjunto de sentimentos negativos com relação à gordura e rejeição às pessoas gordas: "ela tem um rosto tão bonito, pena que é gorda" (Vivi); "eu nunca me peso, mas vejo que engordei pelas minhas roupas, aí eu tranco a boca, não quero ficar gorda!" (Marcela).

Em períodos especiais ganhar peso é até uma benesse, como na gravidez, mas não voltar ao estado normal é sem-vergonhice,

“(...) Na gravidez eu não ligo de ficar gorda, por isso aproveitei para comer tudo que eu podia, na primeira engordei $25 \mathrm{~kg}$ e na segunda $30 \mathrm{~kg}$, graças a Deus perdi tudo, mas tem gente que vai a $100 \mathrm{~kg}$ na gravidez e não volta mais, fica gorda, mas se vê, eu me esforcei, fiz regime, ginástica pra voltar ao meu peso antigo, já pensou se meu marido ia querer ficar com uma gorda?" (Vera)

"Olha, por causa do histórico da minha família, todo mundo meio gordinho, eu e meus irmãos temos desespero com esse negócio de ficar gordo você viu aquele meu irmão? Baixinho, gordinho como meu pai, eu não quero ficar assim não. Minha irmã ficou grávida e fez regime, à noite não janta, só come sopa, eu cortei doce, principalmente chocolate, mas se um dia eu como mais, não tenho dúvida, corro uma hora para queimar tudo que comi a mais!" (Marcelo)

De qualquer forma, o conhecimento do controle alimentar existe, mas as restrições variam, alguns se mostraram mais preocupados que outros. Vale lembrar que muitas entrevistas foram feitas em praças de alimentação, e uma observação recorrente era referir-se aos alimentos dos restaurantes ali localizados como porcarias, culpados pela atual onda de obesidade. Nesse sentido, o eixo do saudável/não saudável era utilizado para classificar hierarquicamente os restaurantes e a comida de casa. Os obstáculos para uma dieta saudável seriam aqueles impostos pelos prazeres oferecidos na rua, já que em casa a comida sempre 
é mais saudável: sabe-se quem é o responsável do preparo, quais os ingredientes utilizados, como foi feito, a higiene, de modo que é uma comida que raramente faz mal.

Outra questão com relação ao alimento e seu impacto sobre a saúde é como se lida com a higiene e a manipulação dos alimentos, pois um medo constante entre os interlocutores era adquirir algum tipo de doença devido à má conservação, um preparo descuidado ou uso de produtos com datas de validade vencidas, além das frequentes menções a insetos. A presença de baratas, formigas, moscas seria indicativa de que a comida não é de boa qualidade, especialmente quando exala um cheiro diferente, estranho. A fim de evitar uma surpresa esses itens eram observados, especialmente na refeição fora de casa, criando uma espécie de administração de risco hierarquizada, sobretudo, no eixo espacial: comida consumida na rua nunca era uma opção recomendável, apenas servia para resolver um problema imediato; um restaurante de comida por quilo não deveria ser frequentado após as $14 \mathrm{~h}$, tá tudo velho; alguns preferiam estabelecimentos que esquentavam ou fritavam alimentos após o pedido, por ser mais fresquinho, nessa categoria até alguns mencionaram a rede de lanchonetes McDonald's, observando que se um alimento pronto ficasse por mais de cinco minutos na prateleira seria descartado.

Outro vilão da boa forma, segundo os interlocutores, seria o lanche, ${ }^{14} \mathrm{embora}$ com cono-

\footnotetext{
${ }^{14}$ O lanche, na definição de Douglas (1975), e no sentido atribuído por Fischler (1990), é uma espécie de consumo alimentar sem estrutura e entre refeições. Na tentativa de esclarecer o que se define por estrutura é preciso recorrer às ligações do acontecimento alimentar a regras prescritas: ao evento, ao lugar determinado para seu desenrolar, assim como das ações que irão compor a sequência do ato, pressupondo certa sociabilidade. O lanche, por conseguinte, seria desprovido dessa organização, tornando-o um consumo alimentar impreciso, diluído ao longo do dia, sem obedecer a horas específicas, sem definir um alimento apropriado para esse momento, consumido individualmente em grande parte das ocasiões. Rial (1992, 1996) já apontara essa questão em seus trabalhos, notando que há certa nostalgia de estrutura perdida, sobretudo ao analisar detidamente a questão do aumento de ocorrências alimentares, isto é, momentos nos quais se absorvem alimentos, representados pelo incremento de lanches ou snacks, como ela definiu, uma ocorrência alimentar não estruturada uma vez que, ao contrário da refeição, não prescreve normas tais como horários, lugar, quantidade, companhia, tipo de alimento. No entanto, essa questão não se mostra tão fácil, continuou a autora, pois os fast-foods não são lugares somente para o consumo de "lanches" ou ocorrências alimentares não estruturadas, aspecto que se insinuou nos dados coletados neste trabalho, já que, como foi possível entrever, o "lanche" pode substituir "comida" e, mesmo assim, considerar-se que houve uma refeição tomada, embora valorizada segundo os elementos que podem caracterizar essa percepção, como a proximidade com a casa, o preparo, o horário, o tempo empregado
}

tações diferentes entre homens e mulheres. Nas falas femininas, o lanche era sempre negativo, pois implicava no consumo de alimentos considerados porcarias: pão, frios, maionese ou manteiga quando substituía uma refeição, ou doces, balas, bolos etc. quando era ingerido no meio das refeições, transformando-se em belisco. Lanche saudável poderia até acontecer para as mulheres desde que fosse um iogurte ou fruta, para os homens tinha outro apelo, interpretavam o lanche quando substituto do almoço ou jantar como comida de regime, já que tinham fome algumas horas depois de consumi-lo, mas caso fosse consumido no meio das refeições, adquiria uma percepção negativa. Mas, curiosamente, muitos preferiam lanchar à noite no lugar de jantar, a fim de não engordar, pois em geral a quantidade de comida era menor, de modo que não se consome excesso de calorias.

O lanche permaneceu ambíguo em relação à forma física e o número de refeições a serem tomadas diariamente, uma vez que muitos interlocutores, sob a influência de informações recentes, comentaram que fazer pequenos lanches seria mais adequado do que passar horas sem comer, pois "(...) você engana seu corpo, entende? Vai dando de pouquinho em pouquinho e ele acostuma a gastar, daí também não chega morrendo de fome no almoço ou no jantar." (Ediris). Sob um enfoque distinto, outros interlocutores viam aqui uma forma de engordar, pois uma dieta saudável só poderia ser feita a partir de três refeições ao dia, "eu como certo, não fico beliscando, é café, almoço e jantar" (Adriana), fugindo dos "beliscos por serem altamente engordativos, apesar de inocentes". Inocentes porque são associados a um tamanho diminuto e a uma sensação prazerosa quando se consomem, mas de grande ameaça à silhueta, de forma que deveriam ser afastados.

Constitui-se, segundo Fischler (1990), uma lipofobia ${ }^{15}$ seguida pela condenação do açúcar ${ }^{16}$, sendo estes os principais elementos a serem evitados na alimentação atual e estarem associados aos males modernos como problemas cardíacos, excesso de açúcar no sangue (diabetes) e excesso de peso (obesidade). Assim, as tranqueiras e as porcarias são abominadas pelo perigo que representam, de maneira que, além do óleo, os doces também são restritos. Essas categorias também abrangem os beliscos, especialmente porque ainda persiste uma ideia de que comer entre refeições é um hábito prejudicial, embora outros interlocutores

nessa atividade etc.

${ }^{15}$ Termo cunhado pelo autor para denominar o medo à gordura que orienta as preferências alimentares atuais, assim como sua diabolização. ${ }^{16}$ Sobre a trajetória dos significados do açúcar, consultar Mintz (1985). 
bem informados, segundo sua própria percepção, demonstrassem saber que comer três vezes ao dia não se trata mais de algo saudável.

Contudo, a sensação que permaneceu, ao ouvir os comentários, foi a de que estar comendo açúcar e coisas fritas ou gordurosas são agradáveis e oferecem uma espécie de transgressão.

"Não como sempre McDonald's, mas toda sexta eu e o pessoal do escritório vamos lá e comemos tudo que temos direito, aquele pessoal de terno Armani todo lambuzado de catchup, não é legal?" (Marcela)

Doces surgiam mais como alimentos femininos ou infantis e gorduras, masculinas. No entanto, deixar de consumir algum tipo de alimento normalmente começava pelos doces, uma vitória comentada por aqueles que abandonaram o vício, segundo ouvi de boa parte dos interlocutores. Comer doce e contar que o fez era quase uma confissão de fraqueza, afinal era denúncia de maus hábitos.

Sob esse aspecto, é no eixo temporal que se nota maior flexibilidade na alimentação, sobretudo em períodos de lazer e descanso. Passar o fim-de-semana comendo, sair para comer, eram atividades que preenchiam o tempo livre, embora afetando o cotidiano alimentar. Um hábito que era referido como nocivo em quase todas as falas era consumir alimentos como biscoitos, bolachas, balas, doces, sorvetes entre as refeições, às vezes classificados como lanches, às vezes como beliscos ou qualquer coisa para tapear a fome, hábito que se observou ocorrer com maior disponibilidade de tempo, especialmente fins-de-semana, quando comer tá liberado.

Mudar os hábitos alimentares é uma conquista narrada como árdua e quando alcançada, quer ser reconhecida,

"Olha, mudei muito, você não imagina o que eu comia e agora não aguento nem com o cheiro, a única coisa que eu ainda não resisto muito é o lanche do McDonald's, mas já larguei um monte de porcaria: maioneses, fritura, doces só light e estou conseguindo manter o peso. Ainda falta (olhando para o corpo), mas estou chegando lá." (Gisele).

Para muitos, se as "escapadas" da alimentação controlada devem ficar nos fins de semana ou períodos de descanso, elas têm um preço que é ser mais rigoroso com a dieta nas refeições seguintes, muitas vezes revelando um sentimento de que "o corpo não resistiu à tentação, foi mais forte que minha vontade, essa coisa de querer mesmo" (Maria Lúcia), afetando a percepção de seu "eu", à medida que não se consegue resistir às porcarias, ou "se for para estragar o regime que seja com uma coisa boa, não qualquer coisa". (Adriana). O impulso deve ser domesticado, pois do contrário a marca corporal se instala e todas as decorrências dela: rejeição, doenças, estigma.

Para os mais velhos, lidar com dificuldades no peso já se torna normal, o importante é administrar a saúde, de modo que também as restrições devem ser observadas a fim de não desequilibrar o corpo.

Neste primeiro levantamento das categorias de saúde e doença relacionadas ao comer, algumas não emergiram, outras ficaram latentes, sobretudo por causa do recorte, mas pouco se comentou sobre doenças, como câncer, decorrentes da alimentação. O principal aspecto apontado estava sempre relacionando comer, obesidade e as desordens que poderiam ser desenvolvidas por estar fora do peso, além do comprometimento da imagem social, associada ao descontrole, à fraqueza de espírito, de um ser pobre coitado que não consegue controlar seus impulsos com relação à comida, além de ter outros problemas de ordem psicológica. Ou seja, para o grande saber produzido em torno da alimentação, o controle mais profundo se exerce no corpo social, embora as escolhas e decisões sejam do indivíduo que precisam ser vigiadas e monitoradas a fim de escapar à desordem que um corpo obeso acarreta em nossa sociedade contemporânea.

\section{CONCLUSÕES}

A alimentação como emergiu nas falas analisadas se mostrou fundamental para a construção de uma subjetividade que se manifesta materialmente no corpo. Não creio que seja o caso de afastar-se totalmente das representações, como parece ocorrer em Foucault, uma vez que há um evidente diálogo entre o que está fora do corpo e aquilo que está dentro, influenciado pelos discursos e na ação. No entanto, a corporalidade como um processo é e sempre será incompleta, de modo que restaria alguma agência ao sujeito no momento em que a ordem se reproduz.

É nessa perspectiva que a relação entre comer e saúde possa contribuir para a questão da materialidade corporal, afinal seria possível pensar 
esse processo agindo sob um único modelo? Qual o papel das representações? Em que medida os discursos afetam as escolhas de um sujeito que se supõe não ter vontade? De que modo essa ordem é tão hegemônica? Quais as situações limite? Que práticas organizam o consumo do alimento do modo que o presenciamos? São algumas questões ainda em aberto.

É inegável que lógicas culturais atuam na construção do que é comestível/ não comestível e, por extensão o que se incorpora ao comer, dando-lhe uma materialidade anterior à forma e significação, segundo Foucault. Mas não pode ser tomado como universal, já que o corpo adquire consistência no campo social e no interior de algumas "grades reguladoras de inteligibilidade." (BUTLER, 2003: 188).

Para pensar as representações do comer, a distinção entre natureza e cultura é dada como "falsa questão" no entender de Fischler (1990), pois essa diferença é apenas mais um recurso de nossa maneira de pensar ocidental para entender problemas que nos incomodam. Visivelmente esse é o cerne do pensamento de Latour (1994), pois como este afirmou: "Natureza e sociedade não oferecem nenhuma base sólida sobre a qual possamos assentar nossas interpretações (...)" (Op.Cit: 95). Os autores analisados trazem uma discussão em torno dos embates políticos e disputas de poder que essa materialização dos corpos traz consigo sob o ponto de vista da doença como desordem e tratar a obesidade como uma medicalização, um fenômeno que sempre existiu, mas que adquire outro estatuto frente a articulações políticas que se inscrevem corporalmente e que constituem hierarquias, diferenças, dominação, opressão, disputas.

O que está em jogo é a escolha teórica e os seus rendimentos para a análise de problemas etnográficos específicos que a distinção entre natureza e cultura permite vislumbrar a partir de sua abordagem. Não se trata somente de definir o que pertence a cada divisão, o próprio uso dessa noção e sua escolha como instrumento de análise tem implicações políticas diretas que nunca serão neutras.

Sobre esse último ponto, não há como deixar de concordar com Foucault que para entender a complexidade desse ponto, saberes locais ou os exemplos etnográficos específicos podem ampliar a profundidade das análises e, se não contribuem para obter uma resposta definitiva, ao menos trazem mais elementos para reflexão. Esses saberes localizados, contudo, são parte das várias realidades circulando pelo mundo e, embora tenhamos a ilusão de serem isoladas pelas definições estáticas oferecidas pela ciência que optou em estabelecer natureza e cultura em lados opostos, há um diálogo evidente, especialmente quando articuladas sobre o corpo.(LATOUR, Op.Cit)

No entanto, se o discurso científico hegemônico tenta impor sua visão, tampouco se pode descuidar do fato de que essa luta é por campos em busca de legitimidade e poder, pois é preciso aprofundar essa noção de domínio da ciência, construída por homens e seus interesses. Diferentes materialidades, diferentes realidades, diferentes estatutos simbólicos que dialogam entre si para lembrar que o externo e o interno não são reconhecidos pelas suas fronteiras exatas, mas evidentes pelo seu caráter publico.

\section{REFERÊNCIAS}

BEARDSWORTH, Alan. Trans- science and moral panics: Understanding food scares. British Food Journal, 92, 5, 1990.

BEARDSWORTH, Alan. The management of food ambivalence: Erosion and Reconstruction? MAURER, D. \& SOBAL, J. Eating agendas: Food and nutrition as social problems. Nova York: Aldine de Gruyter, 1995.

BOLTANSKI, Luc. As classes sociais e o corpo. Rio de Janeiro: Graal, 1989.

BONIN, Ana Maria e ROLIM, Maria do Carmo. Hábitos alimentares: tradição e inovação. Boletim de Antropologia, Curitiba: UFPR, Departamento de Antropologia, v.4, no. 1, junho, 1991.

BORDO, Susan. Unbearable Weight. Berkeley: University of California Press, 1993.

BOURDIEU, Pierre. La distinction. Paris: Éditions Gallimard, 1979.

BRILLAT-SAVARIN. A fisiologia do gosto. São Paulo: Companhia das Letras, 1995.

BUTLER, Judith. Fundamentos Contingentes: O feminismo e a questão do 'pós-modernismo. Cadernos Pagu (11), 1988, p11-42.

BUTLER, Judith. Corpos que pesam: sobre os limites discursivos do 'sexo'. In: LOURO, Guacira Lopes (org.). O corpo educado. Belo Horizonte: Autêntica, 
2001.

FALK, P. The consuming body. London: Sage, 1994.

BUTLER, Judith. Problemas de gênero. Rio de Janeiro: Civilização Brasileira, 2003.

CARRARA, Sérgio. Uma 'tempestade' chamada Latour: a antropologia da ciência em perspectiva. Physis, volume 12, número 1, 2002.

CAPLAN, Pat. Food, health and identity. London: Routledge, 1997.

CHEN, Nancy N. Food, medicine and the quest of good health. Nova York: Columbia University Press, 2009.

COLLAÇO, Janine H.L. ; MENASCHE, Renata; ALVAREZ, Marcelo e (orgs.). Dimensões socioculturais da alimentação: diálogos latino-americanos. Porto Alegre: Editora UFRGS, 2012.

COLLAÇO, Janine Helfst Leicht. Saberes e Memórias: cozinha italiana e construção identitária em São Paulo. Tese de Doutoramento apresentada ao Departamento de Antropologia da FFLCH/USP, 2009.

COLLAÇO, Janine Helfst Leicht. Restaurantes de comida rápida em praças de alimentação de shopping-centers: Soluções à moda da casa. Dissertação de mestrado defendida pelo Departamento de Antropologia Social da Faculdade de Filosofia, Letras e Ciências Humanas da Universidade de São Paulo - FFLCH/USP, 2003.

COUNIHAN, Carole \& VAN ESTERIK, Penny (eds.). Food and culture. Nova York: Routledge, 1997.

DOUGLAS, Mary. Implicit meanings. London: Routledge \& Kegan Paul, 1975.

DUARTE, Luiz Fernando Dias. A sexualidade nas ciências sociais: leitura crítica das convenções. In: PISCITELLI, Adriana; GREGORI, Maria Filomena; CARRARA, Sérgio (orgs.). Sexualidade e saberes: convenções e fronteiras. Rio de Janeiro: Garamond, 2004.

ELIAS, Norbert. O processo civilizador. Rio de Janeiro: Jorge Zahar, 1994, v.1.

ELIAS, Norbert. O processo civilizador. Rio de Janeiro: Jorge Zahar, 1993, v.2.
FISCHLER, Claude. L'Homnivore. Paris: Édition Odile Jacob, 1990.

FOUCAULT, Michel. A história da sexualidade. Rio de Janeiro: Graal, 1988.

FOUCAULT, Michel. Microfsísica do poder. Rio de Janeiro: Graal, 1990.

FOUCAULT, Michel. Vigiar e punir. Petropólis: Editora Vozes, 1991.

GONÇALVES, Clarissa Azevedo. O ‘peso' de ser muito gordo. Mneme, volume 5, número 11,

jul/set/ 2004.

LATOUR, Bruno. Jamais fomos modernos. Rio de Janeiro: Editora 34, 1994.

LATOUR, Bruno. How to talk about the body? The normative dimension of science studies. Body and society. Special issue, November, 2002.

LEVENSTEIN, Harvey. Revolution at the table. Berkeley: University of California Press, 2003.

LEVENSTEIN, Harvey. The paradox of plenty. Berkeley: University of California Press, 2003.

LUPTON, Deborah. Food, body and the self. London: Sage, 1996.

MENNELL, Stephen. All manners of food. Illinois: University of Illinois Press, 1996.

MINTZ, Sidney. Food and anthropology: a brief overview. Revista Brasileira de Ciências Sociais Outubro 2001, vol.16, no. 47, p. 31-42. Disponível em: http://www.scielo.br/scielo.php?script=sci artex\&pid $=$ S0102 $-69092001000300002 \&$ Ing $=$ en\&n $\mathrm{rm}=$ iso.Acesso em: 28/10/2002

MINTZ, Sidney. Sweetness and Power: The place of sugar in modern history. Nova York: Penguin Books, 1985.

NESTLE, Marion. Food Politics. Berkeley: University of California Press, 2002.

ORTIZ, Renato. Pierre Bourdieu: Sociologia. São Paulo: Ática, 1994. 
POULAIN, Jean-Pierre. Sociologies de

l'alimentation. Paris: PUF, 2002.

RIAL, Carmen. Fast-food: a nostalgia da estrutura perdida. Horizontes Antropológicos, número 4, 1996, p.94-103

SOBAL, Jeffey. Sociological Analysis of the stigmatization of obesity. In: GERMOV, John \& WILLIANS, Lauren. A sociology of food and nutrition. The social appetite. Nova York: Oxford University Press, 2004.

VASCONCELOS, Francisco de Assis Guedes de. O nutricionista no Brasil: uma análise histórica. Revista de Nutrição, Campinas, 15 (2), maio-ago, 2002, p. 127-138. 